Research Paper

\title{
Total lesion glycolysis in oral squamous cell carcinoma as a biomarker derived from pre-operative FDG PET/CT outperforms established prognostic factors in a newly developed multivariate prediction model
}

\author{
Gerrit Spanier $^{1}$, Daniela Weidt ${ }^{2}$, Dirk Hellwig ${ }^{2}$, Johannes K.H. Meier ${ }^{1}$, Torsten E. \\ Reichert $^{1}$ and Jirka Grosse ${ }^{2}$ \\ ${ }^{1}$ Department of Cranio-Maxillofacial Surgery, University Hospital Regensburg, Regensburg, Germany \\ ${ }^{2}$ Department of Nuclear Medicine, University Hospital Regensburg, Regensburg, Germany \\ Correspondence to: Jirka Grosse, email: jirka.grosse@ukr.de
}

Keywords: FDG PET/CT; TLG; MTV; oral squamous cell carcinoma; prognostic value

Received: September 08, $2020 \quad$ Accepted: December 16, $2020 \quad$ Published: January 05, 2021

Copyright: ( 2021 Spanier et al. This is an open access article distributed under the terms of the Creative Commons Attribution License (CC BY 3.0), which permits unrestricted use, distribution, and reproduction in any medium, provided the original author and source are credited.

\section{ABSTRACT}

Purpose: Retrospective study to investigate the impact of image derived biomarkers from [ ${ }^{18}$ F]FDG PET/CT prior to surgical resection in patients with initial diagnosis of oral squamous cell carcinoma (OSCC), namely SUV max $^{\prime}$ SUV $_{\text {mean }}$ metabolic $^{\prime}$ tumor volume (MTV) and total lesion glycolysis (TLG) of the primary tumor to predict overall survival (OS).

Materials and Methods: 127 subsequent patients with biopsy-proven OSCC were included who underwent $\left[{ }^{18}\right.$ F]FDG PET/CT before surgery. SUV max $^{\prime}$ SUV $_{\text {mean }}$ MTV and TLG of the primary tumor were measured. OS was estimated according to KaplanMeier and compared between median-splitted groups by the log-rank test. Prognostic parameters were analyzed by uni-/multivariate Cox-regression.

Results: During follow-up $52(\mathbf{4 1 \%})$ of the patients died. Median os was longer for patients with lower MTV or lower TLG. SUV max $_{\text {and }}$ SUV $_{\text {mean }}$ failed to be significant predictors for OS. Univariate Cox-regression identified MTV, TLG, lymph node status and UICC stage as prognostic factors. By multivariate Cox-regression MTV and TLG turned out to be independent prognostic factors for $O S$.

Conclusions: The pre-therapeutic [18F]FDG PET/CT parameters MTV and TLG in the primary tumor are prognostic for OS of patients with an initial diagnosis of OSCC. TLG is the strongest independent prognostic factor for OS and outperforms established prognostic parameters in OSCC.

\section{INTRODUCTION}

Oral squamous cell carcinoma (OSCC) is the sixth common malignancy in the world, with around 900,000 cases diagnosed per year. It accounts for $90 \%$ of all head and neck cancers. It is widely understood, that the evolution and progression of this cancer is a result of multiple stepwise alterations in cellular and molecular pathways within the squamous epithelium [1-5]. The main risk factors are tobacco and alcohol abuse and partly infection with human papilloma virus (HPV) $[4,6,7]$. Depending on patient and tumor factors the multidisciplinary therapeutic concept consists of surgery, radiation therapy, chemotherapy and targeted therapies. Despite these regimes and recent advancements in immune therapies the long-term prognosis is still poor, due to a high rate of locoregional recurrence and new malignant conversions [8-10]. Imaging enhances information beyond medical history and physical examination by assessing the tumor extent, possible bone infiltration and the presence of cervical nodal metastases in OSCC [11]. Regarding to this, computed tomography (CT) and magnetic resonance imaging (MRI) are the primary techniques for evaluation. However, there is evidence of a prognostic significance of metabolic biomarkers in positron emission tomography (PET) that cannot be visualized by CT and MRI [12]. 
The traditional and well established TNM staging system is based on the anatomical extent of tumor, metastases and certain histopathological features. Recently, in its eighth version, the American Joint Committee on Cancer (AJCC) introduced several new predictors like depth of tumor invasion and extranodal spread in cervical lymph node metastasis [13]. But it lacks specific biological and molecular properties of the tumor cells. An emerging hallmark of cancer cells amongst others is deregulated energy metabolism $[14,15]$.

Due to the high glucose utilization of many types of cancer PET with $\left[{ }^{18} \mathrm{~F}\right]$ fluorodeoxyglucose (FDG) in combination with $\mathrm{CT}$ is well established in the diagnostic work-up of oncological patients. PET/CT in OSCC is commonly used at initial presentation to assess distant metastatic disease, to evaluate potential primary sites in the setting of an unknown primary cancer, to evaluate physiologic or pathologic activity within borderline cervical adenopathy and for post-treatment residual or recurrent disease [16-19]. FDG PET is superior to CT and MRI in the assessment of cervical, supraclavicular, and mediastinal lymph node involvement in patients with OSCC and in combination with CT or MRI it is supposed to be even more accurate. However, the improved accuracy of detection of distant metastasis and secondary tumors is the major advantage of FDG PET [20-22]. Moreover, FDG PET/CT provides accurate information on metabolic aspects especially in terms of tumor heterogeneity.

Despite its high sensitivity in the detection of cancer in the head and neck area, FDG PET/CT does not offer any advantage over contrast-enhanced CT or MRI in T-staging because the accurate assessment of tumor spread and the relationship between tumor and adjacent structures is difficult in unenhanced low-dose technique. FDG PET/MRI holds promise as an evolving modality in head and neck cancer [23]. On the other hand, PET/CT often enables a more precise contouring of solid tumors as part of therapy planning prior to radiation, which appears to result in better outcome of patients. This may be due to the fact that functional imaging is able to differentiate between malignancy and peritumoral edema. In some cases an early infiltration does not yet show a clear morphological correlate [24, 25].

Other applications in the post-treatment setting are the evaluation for local and distant tumor recurrence. Limiting factors are surgical and particularly radiation therapy-induced tissue alterations that cause increased uptake due to inflammation and can mimic tumor recurrence [19, 26-28]. In a prospective, randomized, controlled study, it could be shown that patients with locally advanced head and neck tumors can avoid surgery after chemoradiation without survival disadvantages if FDG PET/CT shows no pathologic glucose metabolism [19].

The standardized uptake value (SUV) is the typically used measure of glucose metabolism in clinical routine in FDG PET/CT. Reported as maximum $\left(\mathrm{SUV}_{\max }\right)$ or mean tumoral SUV $\left(\mathrm{SUV}_{\text {mean }}\right)$, it does not fully reflect the metabolic properties of all the tumor cells. Lately this led to the introduction of new parameters for the analysis of FDG PET image data which quantify both anatomical and metabolic aspects of the entire tumor and/or metastases.

Metabolic tumor volume (MTV) is an index reflecting the size and extent of tissues with increased glucose metabolism, and total lesion glycolysis (TLG), the product of MTV and the SUV ${ }_{\text {mean }}$, comprehends both anatomical size and metabolic activity. Typically, there is a collinearity between the parameters pT-classification and MTV. Both measures turn out to be independent prognostic biomarkers in various solid malignancies [2931]. In OSCC both can also be used to monitor therapeutic effects and to predict outcome $[32,33]$.

The purpose of this study was to investigate imaging biomarkers derived from pre-treatment FDG PET, including $\mathrm{SUV}_{\max }, \mathrm{SUV}_{\text {mean }}$, MTV and TLG as potential predictors of OS in patients who underwent surgical resection of OSCC as primary treatment. Furthermore, to develop a multivariable prediction model for OS and to compare its prognostic value with established prognostic factors such as cervical lymph node status and UICC stage.

\section{RESULTS}

\section{Patient characteristics}

Of the 138 consecutive patients, 11 patients were excluded according to the selection criteria as shown in Figure 1. Therefore, a total of 127 patients was included in this analysis: 93 men and 34 women with an age of $60 \pm 10$ years (range 35-83 years). The most frequent tumor site was the floor of the mouth. Smoking history was reported in 106 patients (83.5\%), alcohol abuse in 93 patients $(73.2 \%)$. Eighty patients $(63 \%)$ had an advanced UICC stage III or IV, 60 patients had lymph node metastases (47.2\%). Baseline clinical characteristics of enrolled patients are listed in Table 1.

\section{FDG PET derived parameters}

A typical example of a patient with an OSCC in the floor of the mouth is demonstrated in Figure 2. Table 2 gives an overview for each of the parameters $\left(\mathrm{SUV}_{\max }\right.$, $\left.\mathrm{SUV}_{\text {mean }}, \mathrm{MTV}, \mathrm{TLG}\right)$ measured in the pre-operative FDG PET/CT of the primary tumor with the corresponding median, mean, standard deviation (SD), maximum, minimum, and interquartile ranges (IQR).

For the comparison between patients with and without histologically confirmed cervical lymph node metastases $(\mathrm{N}+)$, higher levels of $\mathrm{SUV}_{\text {max }}(16.8 \pm 6.6 \mathrm{vs}$. $11.9 \pm 6.7, P<0.001), \mathrm{SUV}_{\text {mean }}(10.1 \pm 4.3$ vs. $7.1 \pm 4.1$, $P<0.001)$ and TLG $(75.8 \pm 70.0$ vs. $46.2 \pm 62.3, P<$ 
$0.001)$ were found, whereas only a trend was observed to higher MTVs $(7.1 \pm 5.0$ vs. $6.1 \pm 5.9, p=0.063)$. In the comparison between patients with UICC stage I+II and UICC stage III+IV, advanced stages exhibit higher $\mathrm{SUV}_{\text {max }}$ $(16.7 \pm 7.1$ vs. $10.0 \pm 4.6, P<0.001), \mathrm{SUV}_{\text {mean }}(10.1 \pm 4.6$ vs. $5.9 \pm 2.7, P<0.001), \mathrm{TLG}(80.9 \pm 77.4$ vs. $25.1 \pm 15.0$, $P<0.001)$ and MTV $(7.9 \pm 6.4$ vs. $4.4 \pm 2.1, P<0.001)$.

\section{Survival analysis}

The median follow-up was 63 months with a known status for all patients at 36 months. During the follow-up period, 52 of 127 patients $(40.9 \%)$ died. Median overall survival in the cohort was 83 months (CI: 60-106 months).

Kaplan-Meier survival analysis showed a shorter OS of patients with lymph node metastasis ( $P(\log$-rank) $=0.004$; as shown in Figure $3 \mathrm{~A})$ and with an UICC stage $>$ II $(P(\log$-rank $)=0.018$; as shown in Figure $3 \mathrm{~B})$. In addition, a significant shorter median OS (59 months) could be observed in patients whose primary tumor had a MTV $>5.3 \mathrm{~cm}^{3}(P(\log$-rank $)=0.004)$, whereas a MTV of $\leq 5.3 \mathrm{~cm}^{3}$ was associated with an OS of 95 months (Figure 3C). Similarly, a higher TLG $>38.7 \mathrm{~g}$ was associated with shorter median OS (95 vs. 47 months, $P$ (log-rank) $<0.001$; as shown in Figure 3D). The PET parameters $\mathrm{SUV}_{\text {max }}$ and $\mathrm{SUV}_{\text {mean }}$ were not prognostic for OS.

In univariate analysis, lymph node status, UICC stage, MTV, and TLG were significant predictors for overall survival (Supplementary Table 1).

Due to the fact that TLG is the product of MTV times $\mathrm{SUV}_{\text {mean }}$ there is a strong correlation between MTV and TLG $(r=0.812, P<0.001)$. Thus 2 separate models including either MTV (Model A, Supplementary Table 1) or TLG (Model B, Supplementary Table 1) were used for multivariate Cox regression analyses. Multivariate analyses showed that both MTV (HR 1.991 (CI 1.121$3.500), P($ log-rank $)=0.019)$ and TLG (HR 2.808 (CI $1.563-5.047), P($ log-rank $)=0.001)$ were prognostic factors for overall survival. According to its higher HR the TLG of the primary tumor results in the strongest independent prognostic parameter for OS.

\section{DISCUSSION}

The aim of this retrospective study was to investigate the prognostic value of image derived biomarkers from $\left[{ }^{18} \mathrm{~F}\right] \mathrm{FDG} \mathrm{PET} / \mathrm{CT}$ performed prior to surgical resection in patients with initial diagnosis of OSCC. We focused on $\left[{ }^{18} \mathrm{~F}\right]$ FDG metabolic parameters $\mathrm{SUV}_{\max }, \mathrm{SUV}_{\text {mean }}, \mathrm{MTV}$ and TLG of the primary tumor to evaluate the impact on OS. In addition, the prognostic value of these parameters was compared with established clinical prognostic factors such as UICC stage and lymph node status.

Our study shows that MTV and TLG of the primary tumor are prognostic indicators of OS in patients at initial diagnosis of OSCC. Moreover, TLG is the strongest independent prognostic factor for OS and outperforms established prognostic parameters in OSCC like UICC stage and lymph node metastases. In contrast, PET parameters $\mathrm{SUV}_{\text {max }}$ and $\mathrm{SUV}_{\text {mean }}$ failed to be significant predictors of OS.

Different $\left[{ }^{18} \mathrm{~F}\right]$ FDG PET scan derived parameters have been investigated in several tumor entities like lung cancer [34], head and neck cancers [32, 35, 36], solid tumors and in hemoblastoses/lymphomas [37-40].

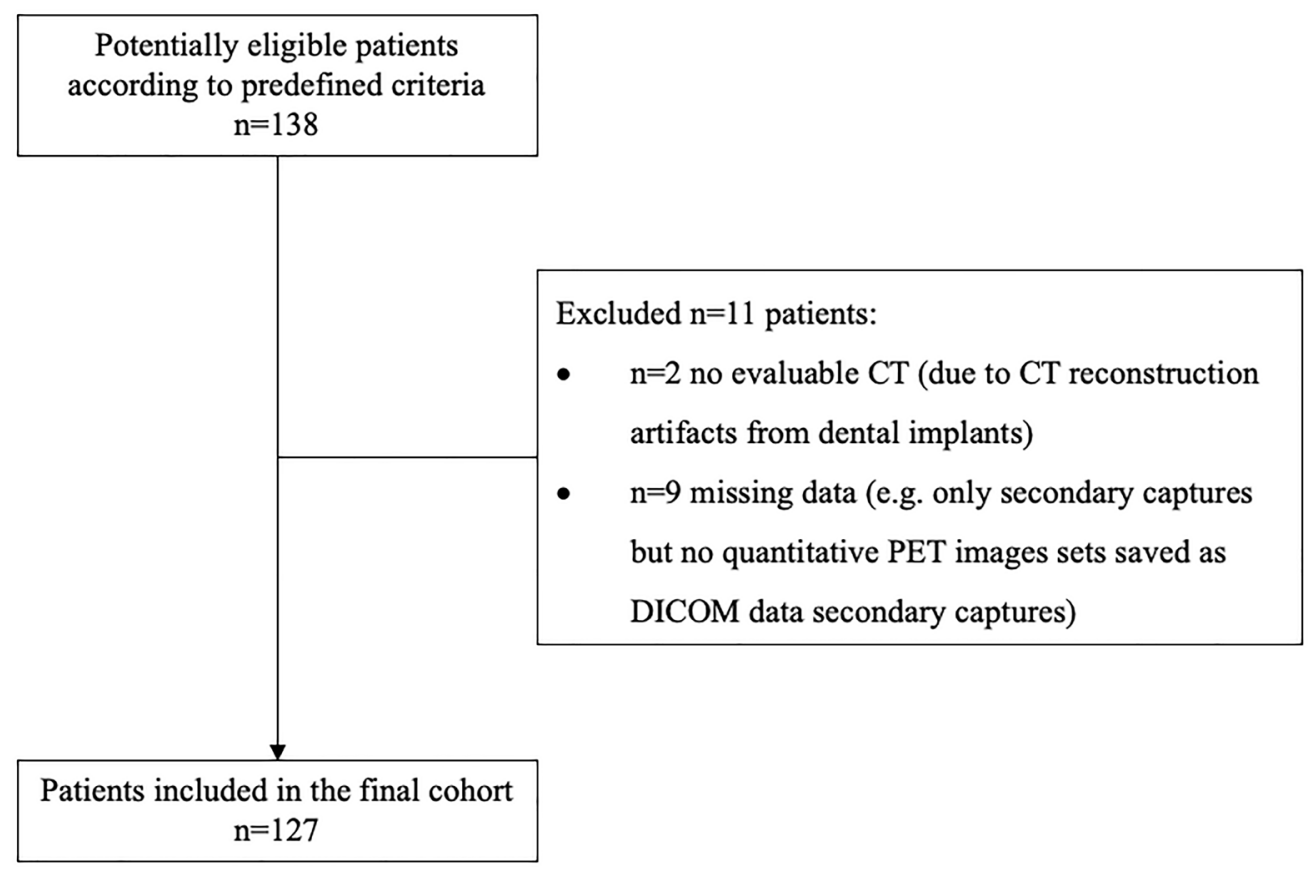

Figure 1: STARD (Standards for Reporting of Diagnostic Accuracy Studies) flow diagram. 


\begin{tabular}{|c|c|}
\hline Parameter & Patients \\
\hline \multicolumn{2}{|l|}{ Sex } \\
\hline Male & $93(73.2 \%)$ \\
\hline Female & $34(26.8 \%)$ \\
\hline \multicolumn{2}{|l|}{ Age (years) } \\
\hline Range & $35-83$ \\
\hline Mean & $60 \pm 10$ \\
\hline Smoking, $n(\%)$ & $106(83.5 \%)$ \\
\hline Alcohol drinking, $n(\%)$ & $93(73.2 \%)$ \\
\hline Smoking and alcohol drinking, $n(\%)$ & $87(68.5 \%)$ \\
\hline \multicolumn{2}{|l|}{ Anatomical site, $n(\%)$} \\
\hline Buccal mucosa & $10(7.9 \%)$ \\
\hline Upper alveolus and gingiva & $7(5.5 \%)$ \\
\hline Lower alveolus and gingiva & $29(22.8 \%)$ \\
\hline Hard palate & $3(2.4 \%)$ \\
\hline Tongue & $13(10.2 \%)$ \\
\hline Floor of mouth & $65(51.2 \%)$ \\
\hline \multicolumn{2}{|l|}{ Cervical lymph node metastases } \\
\hline Yes & $60(47.2 \%)$ \\
\hline No & $67(52.8 \%)$ \\
\hline \multicolumn{2}{|l|}{ UICC stage } \\
\hline$\leq \mathrm{II}$ & $47(37 \%)$ \\
\hline$>$ II & $80(63 \%)$ \\
\hline \multicolumn{2}{|l|}{ Adjuvant therapy } \\
\hline None & $58(45.7 \%)$ \\
\hline Radiotherapy & $41(32.3 \%)$ \\
\hline Radio-chemotherapy & $28(22.0 \%)$ \\
\hline \multicolumn{2}{|l|}{ Survival status } \\
\hline Dead & $52(40.9 \%)$ \\
\hline Alive & $75(59.1 \%)$ \\
\hline
\end{tabular}

In a retrospective study published by Higgins et al. in 2012, 88 patients with head and neck cancer were examined with $\left[{ }^{18} \mathrm{~F}\right] \mathrm{FDG}$ PET prior to definitive treatment by radiotherapy [41]. $\mathrm{SUV}_{\text {mean }}$ was determined in the primary tumor and lymph nodes. Patients with pretreatment tumor $\mathrm{SUV}_{\text {mean }}$ that exceeded the median value demonstrated inferior 2-year disease-free survival with $58 \%$ whereas a $\mathrm{SUV}_{\text {mean }} \leq$ the median value of 15.4 was associated with a longer disease-free survival $(82 \%$, $p=0.03$ ). Our results in OSCC before surgery cannot confirm the observations of the retrospective study of Higgins et al. . We found no association of SUV $\mathrm{Sean}_{\text {and }}$ aS. In the univariate Cox regression, there was no difference in OS between patients with SUV ${ }_{\text {mean }}$ below or above the median of $7.3(\mathrm{HR}=1.451, \mathrm{CI} 0.835-2.521, p=0.187)$. This discrepancy of the results may be related to several factors like different tumor entities (head and neck cancer located in oropharynx $66 \%$ of the patients versus OSCC) in different populations (radiotherapy candidates versus resected patients) investigated with different $\mathrm{PET} / \mathrm{CT}$ scanners (GE Healthcare versus Siemens Healthineers). Whether $\mathrm{SUV}_{\text {mean }}$ is prognostic is best clarified in a prospective trial with well-defined populations.

The prognostic impact of $\mathrm{SUV}_{\max }$ in head and neck cancer has been a subject of research for a number of years, with conflicting results [42-48]. Many studies have shown that $\mathrm{SUV}_{\max }$ of the primary tumor is a significant prognostic factor for survival and an elevated $\mathrm{SUV}_{\text {max }}$ is associated with a poor clinical course [43, 45, 47, 48], whereas others did not support this association [49-51]. Alluri et al. conclude that these inconsistencies might be the result of the heterogeneity regarding tumor stage, tumor site, treatment modalities and the use of different outcome endpoints [52]. Moreover, technical differences between different PET scanners as well as imaging protocols may affect the comparability of quantitative PET measures between centers [53].

In their study Dibble et al. discussed the limited significance of the $\mathrm{SUV}_{\max }$ [49], a parameter that represents the highest relative $\left[{ }^{18} \mathrm{~F}\right] \mathrm{FDG}$ accumulation, but 
Table 2: Descriptive statistics of the image-derived biomarkers derived from FDG PET

\begin{tabular}{cccccc}
\hline Parameter & Mean \pm SD & Median & Minimum & Maximum & IQR \\
\hline SUV $_{\text {max }}$ & $14.2 \pm 7.1$ & 12.8 & 3.9 & 38.2 & $8.8-17.8=9.0$ \\
SUV $_{\text {mean }}$ & $8.5 \pm 4.5$ & 7.3 & 2.2 & 24.8 & $5.2-11.2=6.0$ \\
MTV & $6.6 \pm 5.5$ & 5.3 & 1.4 & 43.6 & $3.1-8.0=4.9$ \\
TLG & $60.2 \pm 67.6$ & 38.7 & 5.3 & 444.7 & $21.0-73.1=52.1$ \\
\hline
\end{tabular}

IQR: Inter-quartile range.

is not representative for volume and biological activity of the entire tumor.

In our study, $\mathrm{SUV}_{\max }$ of the primary tumor was not associated with OS in patients with OSCC. The different results of various studies in head and neck cancer suggest that the prognostic significance of the $\left[{ }^{18} \mathrm{~F}\right] \mathrm{FDG}-\mathrm{PET}$ parameter $\mathrm{SUV}_{\max }$ is questionable.

MTV, which indicates the volume of viable tumor defined by $\left[{ }^{18} \mathrm{~F}\right] \mathrm{FDG}$ uptake, is thought to be a more valuable predictor than $\mathrm{SUV}_{\max }$ [54]. Several previous studies showed that MTV is a predictor for survival in patients with head and neck cancer. However, many of these studies included patients with tumors at different sites of the head and neck region which led to heterogeneity in the investigated cohort [49, 51, 54, 55]. Head and neck squamous cell carcinoma (HNSCC) are clinically heterogeneous entities that show variations in clinical behavior depending on the primary site. Studies that enroll patients with HNSCC of the entire head and neck region may be biased.

In the present study, we included only patients with OSCC prior to surgical resection to minimize the effect of heterogeneity. Ruy et al. also focused on patients with OSCC and found that pretreatment MTV is an independent prognostic factor for overall survival $(n=105, \mathrm{HR}=3.07$; $p=0.001)$. They concluded that an MTV threshold of 3.0 $\mathrm{mL}$ may be useful to stratify the likelihood of survival and to predict occult metastases [50]. In contrast to our study, MTV was determined not only from the primary tumor but also included locoregional lymph node metastases.

Zhang et al. demonstrated the prognostic value of MTV (as defined by the primary tumor and local lymph node metastases) first in a study with a relatively small number of 80 patients with OSCC compared to the present
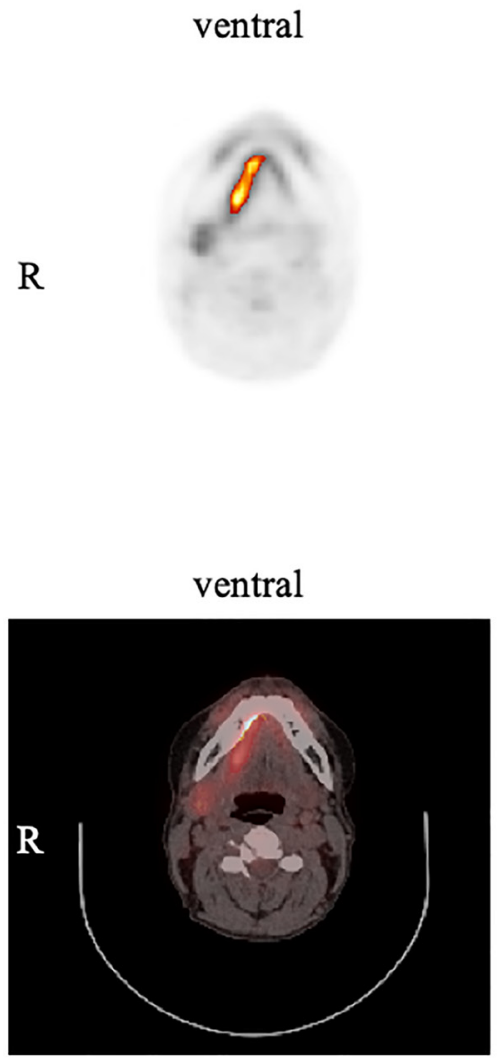

cranial
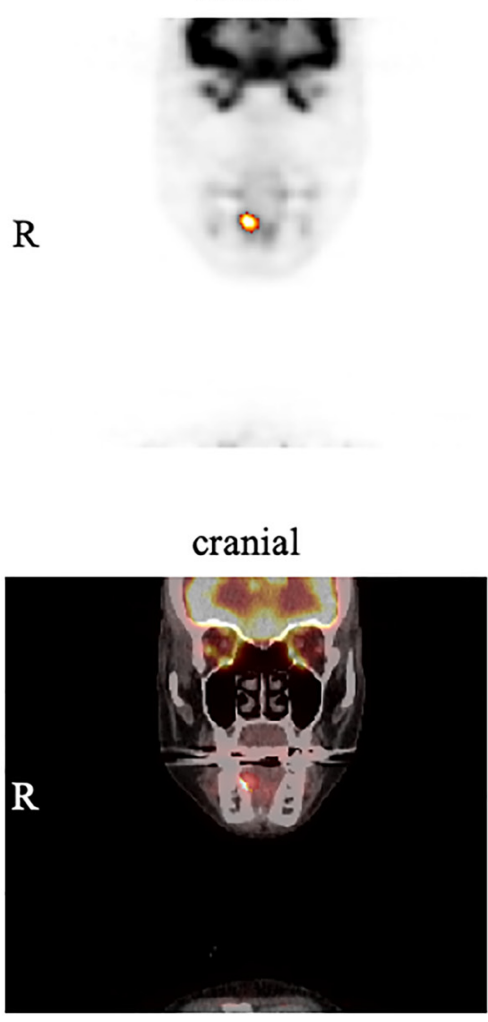

cranial

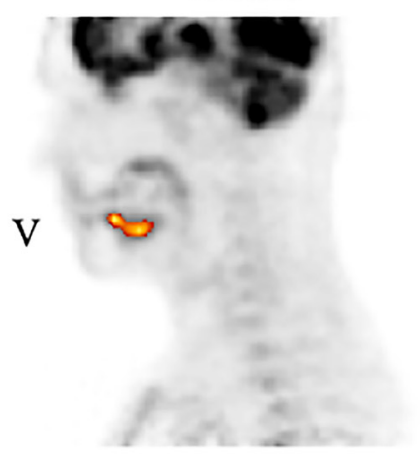

cranial

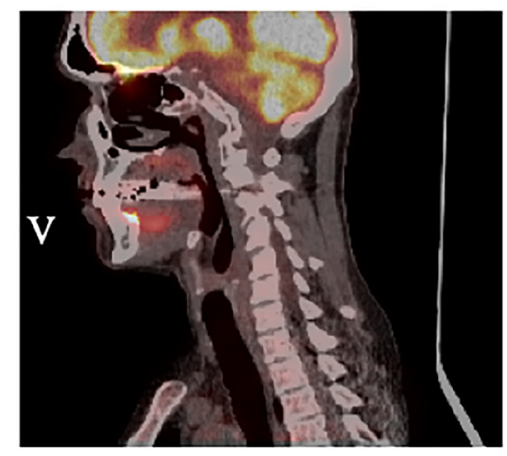

Figure 2: Example of measurements in FDG PET for the primary tumor using the software ROVER. The tumor is located in the right anterior floor of the mouth with an $\mathrm{SUV}_{\max }$ of 12.8. Margins of the tumor were automatically delineated with a relative threshold of $41 \% \mathrm{SUV}_{\max }$ resulting in an MTV of $4.4 \mathrm{~cm}^{3}$ for the primary tumor. 
study [56] and later validated their findings in a smaller cohort in 42 patients with OSCC [44]. An increase in MTV of $17.5 \mathrm{~mL}$ between the lower and upper tertials of the cohorts defined by MTV was associated with a 12.4 fold increase in risk of disease recurrence $(P<0.001)$ and a 11.2 fold increase in the risk of death $(P<0.05)$ [56], as they found during their comparably short follow-up with a mean duration of 1.9 years. Unfortunately, the exact thresholds for MTV derived from solely the primary tumor were not disclosed in the publications, so that a validation of their results in our patient cohort is not possible.

A higher MTV of on one hand tumor and involved lymph nodes $(\mathrm{HR}=9.2, P<0.05)$ as well as on the other hand the primary tumor alone $(\mathrm{HR}=7.0, p=0.0001)$ was associated with statistically significant increase in risk of death [44]. In their validation study MTV was the strongest prognostic parameter in multivariate Cox regression. Although less patients could be enrolled these results support our findings.

We did not include lymph nodes with increased FDG uptake into the MTV. Only tumoral MTV but not nodal MTV was identified as prognostic for survival as other studies found in similar patient populations [44, 51, 57].
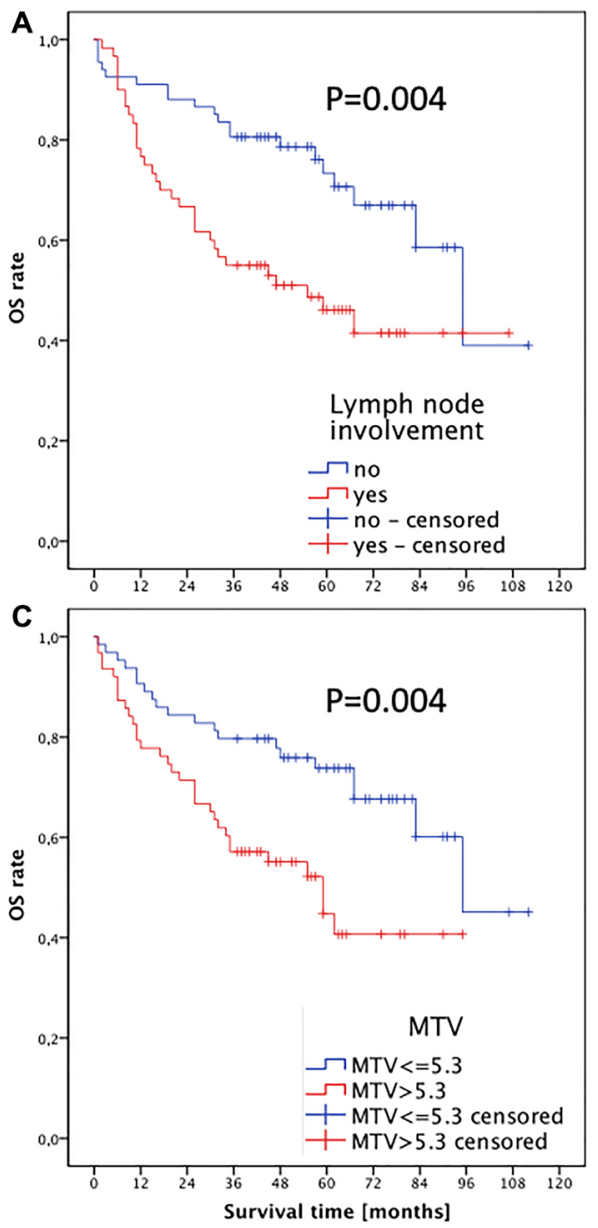

Previous studies demonstrated that TLG is also a possible prognostic predictor for OS of patients with head and neck cancer. TLG, the product of MTV and SUV combines the metabolic and volumetric information of FDG PET [58].

Dibble et al. showed that pretreatment TLG was an independent prognostic factor for $\mathrm{OS}$ in both univariate Cox regression $(\mathrm{HR}=1.00, p=0.006)$ and multivariate Cox regression $(\mathrm{HR}=1.00, p=0.02)$ in patients with oral and oropharyngeal SCC $(n=45)$ and may provide prognostic information in addition to AJCC stage [49]. However, the number of enrolled patients was much smaller compared to our study and the localization of the primary tumor was more heterogeneous.

In the aforementioned study of Ruy et al. in 105 patients with the initial diagnosis of OSCC, TLG could be established as a significant independent prognostic factor for $\mathrm{OS}(\mathrm{HR}=3.50, p=0.002)$ [50]. In contrast to our study, TLG was measured in the primary tumor as well as in lymph node metastases.

These published studies demonstrate the prognostic value of MTV and TLG in patients with OSCC and confirm the results of our study, where TLG is not only
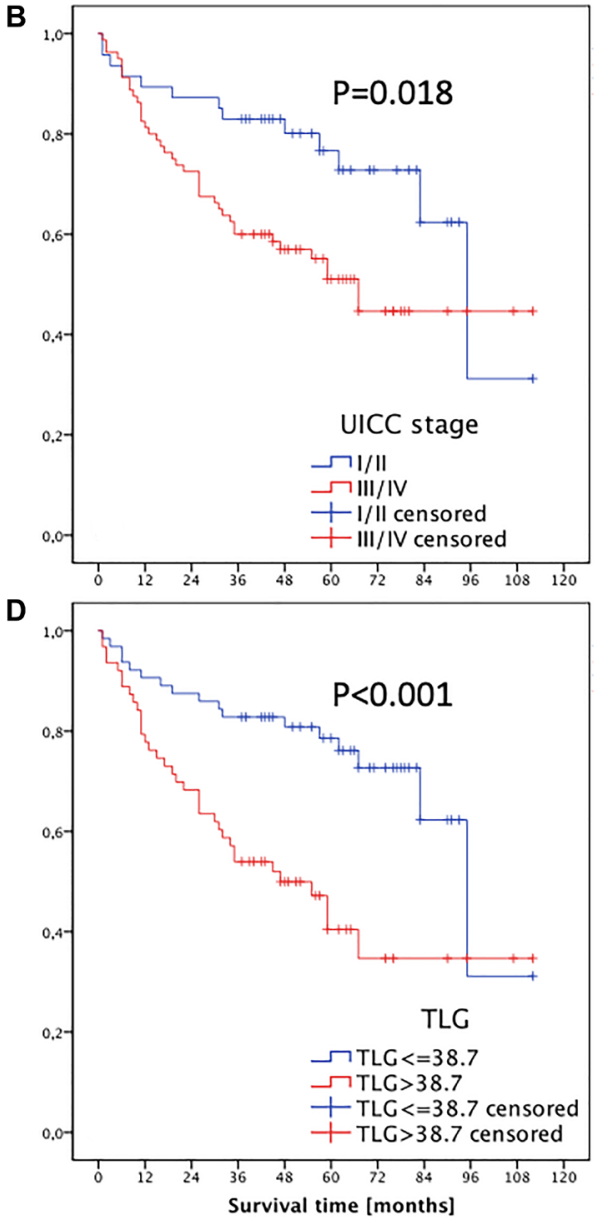

Figure 3: Kaplan-Meier analysis of overall survival for (A) cervical lymph node status, (B) UICC stage, (C) MTV and (D) TLG of the primary tumor. 
an independent prognostic parameter, but the strongest predictive parameter for OS with respect to all investigated potential prognostic parameters $(\mathrm{HR}=2.808, p=0.001)$.

However, the differences between our study and the other studies must be taken into account. Results have to be interpreted carefully in the context of the retrospective study design. The number of patients enrolled, and the period of follow-up were limited, albeit higher than in many previously published studies. Due to poor tumor delineation in native low-dose technique volumetric data of CT were not included.

HPV infection is no relevant prognostic parameter in current TNM staging and was not assessed in this study. In addition, HPV status has no effect on the prognosis of OSCC patients compared to other HNSCC locations. Several authors rate the influence of HPV-triggered carcinogenesis in OSCC as minor [59,60].

Transparent reporting of prediction models including thresholds used for the definition of subgroups is required for reproducibility results and validation of previous observation. Unfortunately, several publications cited here fail to meet these criteria which impedes verification. We have oriented to the TRIPOD standard for our report [61].

In conclusion, TLG and MTV reflect the metabolic burden of the primary tumor more precise than $\mathrm{SUV}_{\text {max }}$ and $\mathrm{SUV}_{\text {mean }}$ and may have superior prognostic value in patients with OSCC compared to other FDG PET parameters und established prognostic clinical parameters. Because OSCC patients with a higher MTV and TLG of the primary tumor prior to treatment have poor OS, FDG PET/CT may be useful for risk stratification. Thus, the measurement of these metabolic parameters could be helpful to select treatment and follow-up strategies such as more extensive surgery and aggressive adjuvant chemoradiation.

A recent meta-analysis by Creff et al. evaluated 36 studies about the prognostic significance of preoperative FDG-PET/CT parameters in HNSCC and suggested them as valuable biomarkers. With $\mathrm{SUV}_{\text {max }}$ as the most commonly measured factor, they confirmed that the volumetric parameters (MTV, TLG) presented a higher prognostic value for several primary endpoints. Six studies focused on the oral cavity with a range of 28-148 participants (median 75.5) and the results were in line with our data [62].

These results need to be confirmed in a retrospective study using an independent data set or even better validated in a prospective study. Radiomics is an emerging and promising approach to research in medical imaging. It is contemporary in transition to clinical practice and needs to overcome several obstacles in terms of standardization, validation and software integration for a feasible clinical workflow.

In the future, image-derived biomarkers from FDG PET/CT may be implemented in risk stratification to manage therapy strategies in patients with OSCC.

\section{MATERIALS AND METHODS}

\section{Patients and clinical data}

In this retrospective study, all subsequent patients with newly diagnosed OSCC between 2006 and 2013 were included who underwent an [18F]FDG PET/CT scan in the Department of Nuclear Medicine (University Hospital Regensburg, Regensburg, Germany) for initial staging prior to surgery. Only patients without neoadjuvant treatment were included. Patients with proven distant metastasis at the time of staging mostly received systemic therapy (depending on the decision of the tumor conference combined with local radiotherapy) and were not enrolled in the study. All included patients underwent surgical resection of the primary intraoral lesion to negative histopathologically proven margins and neck dissection based on the clinical and imaging findings in the Department of Cranio-Maxillofacial Surgery (University Hospital Regensburg, Regensburg, Germany). A total of 127 patients met the criteria and were enrolled in the study.

All patients were staged accordingly to the Union for International Cancer Control (UICC) guidelines in its seventh edition. Patient data were obtained by review of the medical records containing documentations of structured patient interviews prior to surgery. The data included age, weight and height at diagnosis, sex, history of smoking and drinking habits, tumor site, tumor-nodemetastasis (TNM) stage, tumor grade and resection status.

Adjuvant treatment was based on the recommendation of the multidisciplinary tumor board, and radiotherapy and systemic therapy was performed accordingly. Disease progression was defined as local disease recurrence or distant metastasis by radiologic evidence with clinical correlation or histologic confirmation with biopsy. Data concerning OS were obtained from medical records and the clinical cancer register Regensburg (Germany).

Approval from the local ethics committee of the University Hospital Regensburg was obtained (reference number 16-104-0191), and this retrospective study was performed in accordance with all relevant guidelines and regulations.

\section{Imaging}

$\left[{ }^{18} \mathrm{~F}\right]$ FDG PET/CT imaging was performed using a Biograph 16 PET/CT scanner (CTI-Siemens, Erlangen, Germany) that consists of a PET detector with an axial and transaxial field-of-view of $162 \mathrm{~mm}$ and $585 \mathrm{~mm}$ and a 16-slice multidetector CT ( $0.5 \mathrm{~s}$ per revolution).

After a fasting period of at least $6 \mathrm{~h}, 3 \mathrm{MBq}$ $\left[{ }^{18} \mathrm{~F}\right]$ FDG per kilogram body weight were injected intravenously (338 $\pm 32 \mathrm{MBq})$. The patients' blood glucose level was below $150 \mathrm{mg} / \mathrm{dL}(8.32 \mathrm{mmol} / \mathrm{L})$. 
Patients were advised to stay in a quiet lying position to minimize muscular $\left[{ }^{18} \mathrm{~F}\right] \mathrm{FDG}$ uptake. In order and to keep potential tracer accumulation in brown fat tissue to a minimum, warming blankets were used to avoid freezing of the patients. Prior to scanning patients were instructed to void the bladder and to remove all metal parts.

After a waiting period of about 60 min postinjection (74 $\pm 19 \mathrm{~min}$ ), the $\mathrm{PET} / \mathrm{CT}$ acquisition was performed with elevated arms to acquire images of the trunk (six to eight overlapping bed positions with $3 \mathrm{~min}$ of PET acquisition time each depending on the patient size) followed by dedicated images of the head and neck with the arms down (two overlapping bed positions with 5 min per bed position). The same area was covered by a low-dose CT scan (tube current $50 \mathrm{mAs}$, tube voltage 120 $\mathrm{kVp}$ ), respectively. No oral or intravenous contrast agents were used.

After correction for attenuation, decay, scatter, and random coincidences, and iterative reconstruction using the ordered subsets expectation maximization algorithm (OSEM) with 4 iterations and 8 subsets PET images (slice thickness $5 \mathrm{~mm}$ ) were scaled to allow SUV measurements. PET and CT images were checked for breathing/motion artifacts.

\section{Image analysis}

Two experienced observers (JG, DW) reviewed the reconstructed and attenuation-corrected $\left[{ }^{18} \mathrm{~F}\right] \mathrm{FDG} \mathrm{PET} /$ CT images visually on the workstation, with reference to maximum intensity projection, PET/CT fusion and CT images, until consensus was reached. The observers were blinded to clinical parameters and patient outcome.

Spherical or ellipsoidal region of interest (ROI) was placed over the hypermetabolic primary lesions visible on PET images to obtain a three-dimensional coverage of the PET positive tumor on axial, sagittal and coronal projections. If necessary, the tumor was manually delineated using the corresponding CT images.

$\mathrm{SUV}_{\text {max }}, \mathrm{SUV}_{\text {mean }}, \mathrm{MTV}$ and TLG of the primary tumor were measured and automatically calculated using ROVER (ABX, Radebeul, Germany). For calculation of the MTV the margins of the tumor were defined using a relative threshold of $41 \%$ of the $\mathrm{SUV}_{\text {max }}$. TLG was defined as $\mathrm{MTV} \times \mathrm{SUV}_{\text {mean }}[58]$.

\section{Statistical analysis}

All statistical analyses were performed using IBM SPSS Statistics Version 24.0 (IBM Corp., Armonk, N.Y., USA). Continuous variables are expressed as mean with standard deviation (SD) or median with ranges, and categorical variables as counted number with portions in percentages. Deviations from normal distribution were visually inspected by graphic analyses, box plot and histograms as well as analyzed by Kolmogorov-Smirnov and Shapiro-Wilk test. Nonparametric Mann-Whitney- $U$ test was used for comparisons of continuous measures between groups.

OS was defined as time from FDG PET/CT until death of any cause or censored at last patient contact. The period for the survival analysis was planned for a minimum follow-up of 36 months for all patients. OS curves were calculated using the Kaplan-Meier method. The log-rank test was used to compare survival between subgroups defined by potentially prognostic parameters at a significance level of $P<0.05$. Subgroups of patients with lower and higher $\mathrm{SUV}_{\max }, \mathrm{SUV}_{\text {mean }}$, MTV and TLG were defined by dichotomization using the respective median.

The Cox proportional-hazards model was used to evaluate prognostic variables for univariate and multivariate prediction of OS. Multivariate analysis was carried out by Cox regression analysis with backward stepwise exclusion. Hereby we started with the full set of variables with stepwise exclusion of the variable with the largest $P$-value keeping only variables with a significance level of $P<0.10$. We repeated this process until no variable in the model had a $P$-value greater than or equal to the significance level in order to identify prognostic factors in respect of the primary endpoint OS. The estimated hazard ratio (HR) and 95\% confidence intervals (CI) were calculated.

Correlation coefficients were calculated and tested for significance according to Spearman. All tests were two-sided, and $P<0.05$ was considered statistically significant.

\section{Ethical approval}

This research study was conducted retrospectively from data obtained for clinical purposes. Approval from the local ethics committee of the University Hospital Regensburg was obtained (reference number 16-1040191), and this retrospective study was performed in accordance with all relevant guidelines and regulations.

\section{Abbreviations}

AJCC: American Joint Committee on Cancer; CI: Confidence interval; CT: Computed tomography; FDG: $\left[{ }^{18} \mathrm{~F}\right]$ fluorodeoxyglucose; HPV: Human papilloma virus; HR: Hazard ratio; IQR: Interquartile ranges; MBq: Megabecquerel; MRI: Magnetic resonance imaging; MTV: Metabolic tumor volume; OS: Overall survival; OSCC: Oral squamous cell carcinoma; PET: Positron emission tomography; SCC: Squamous cell carcinoma; SD: Standard deviation; SUV: Standardized uptake value; $\mathrm{SUV}_{\max }$ : Maximum tumoral standardized uptake value; $\mathrm{SUV}_{\text {mean }}^{\text {max }}$ : Mean tumoral standardized uptake value; TLG: Total lesion glycolysis; TNM: Tumor-node-metastasis; UICC: Union for International Cancer Control. 


\section{Author contributions}

Conceptualization and design: Jirka Grosse, Dirk Hellwig, Gerrit Spanier. Methodology: Dirk Hellwig, Daniela Weidt, Gerrit Spanier. Formal analysis and investigation: Dirk Hellwig, Daniela Weidt, Jirka Grosse, Gerrit Spanier. Figures and visualization: Daniela Weidt, Jirka Grosse, Dirk Hellwig. Writing - original draft preparation: Jirka Grosse, Gerrit Spanier. Writing - review and editing: Dirk Hellwig, Johannes Meier, Torsten E. Reichert. Supervision: Dirk Hellwig. All authors read and approved the final manuscript.

\section{ACKNOWLEDGMENTS}

The authors are grateful to Dr. Frank Hofheinz and Prof. Dr. Jörg van den Hoff for making the software ROVER available. The authors thank Ernst Fuchs for excellent technical support.

\section{CONFLICTS OF INTEREST}

Authors have no conflicts of interest to declare.

\section{REFERENCES}

1. Chi AC, Day TA, Neville BW. Oral cavity and oropharyngeal squamous cell carcinoma--an update. CA Cancer J Clin. 2015; 65:401-21. https://doi.org/10.3322/caac.21293. [PubMed]

2. Gupta B, Johnson NW, Kumar N. Global Epidemiology of Head and Neck Cancers: A Continuing Challenge. Oncology. 2016; 91:13-23. https://doi. org/10.1159/000446117. [PubMed]

3. Haddad RI, Shin DM. Recent advances in head and neck cancer. N Engl J Med. 2008; 359:1143-54. https://doi. org/10.1056/NEJMra0707975. [PubMed]

4. Torre LA, Bray F, Siegel RL, Ferlay J, Lortet-Tieulent J, Jemal A. Global cancer statistics, 2012. CA Cancer J Clin. 2015; 65:87-108. https://doi.org/10.3322/caac.21262. [PubMed]

5. Warnakulasuriya S. Global epidemiology of oral and oropharyngeal cancer. Oral Oncol. 2009; 45:309-16. https:// doi.org/10.1016/j.oraloncology.2008.06.002. [PubMed]

6. Petersen PE. Oral cancer prevention and control-the approach of the World Health Organization. Oral Oncol. 2009; 45:454-60. https://doi.org/10.1016/j. oraloncology.2008.05.023. [PubMed]

7. Tanaka T, Ishigamori R. Understanding carcinogenesis for fighting oral cancer. J Oncol. 2011; 2011:603740. https:// doi.org/10.1155/2011/603740. [PubMed]

8. Bose P, Brockton NT, Dort JC. Head and neck cancer: from anatomy to biology. Int J Cancer. 2013; 133:2013-23. https://doi.org/10.1002/ijc.28112. [PubMed]
9. Ferris RL, Blumenschein G Jr, Fayette J, Guigay J, Colevas AD, Licitra L, Harrington K, Kasper S, Vokes EE, Even C, Worden F, Saba NF, Iglesias Docampo LC, et al. Nivolumab for Recurrent Squamous-Cell Carcinoma of the Head and Neck. N Engl J Med. 2016; 375:1856-67. https://doi. org/10.1056/NEJMoa1602252. [PubMed]

10. Neville BW, Day TA. Oral cancer and precancerous lesions. CA Cancer J Clin. 2002; 52:195-215.

11. Seeburg DP, Baer AH, Aygun N. Imaging of Patients with Head and Neck Cancer: From Staging to Surveillance. Oral Maxillofac Surg Clin North Am. 2018; 30:421-33. https:// doi.org/10.1016/j.coms.2018.06.004. [PubMed]

12. Xie P, Li M, Zhao H, Sun X, Fu Z, Yu J. 18F-FDG PET or PET-CT to evaluate prognosis for head and neck cancer: a meta-analysis. J Cancer Res Clin Oncol. 2011; 137:108593. https://doi.org/10.1007/s00432-010-0972-y. [PubMed]

13. Lydiatt WM, Patel SG, O'Sullivan B, Brandwein MS, Ridge JA, Migliacci JC, Loomis AM, Shah JP. Head and Neck cancers-major changes in the American Joint Committee on cancer eighth edition cancer staging manual. CA Cancer J Clin. 2017; 67:122-37. https://doi.org/10.3322/caac.21389. [PubMed]

14. Fouad YA, Aanei C. Revisiting the hallmarks of cancer. Am J Cancer Res. 2017; 7:1016-36.

15. Pavlova NN, Thompson CB. The Emerging Hallmarks of Cancer Metabolism. Cell Metab. 2016; 23:27-47. https:// doi.org/10.1016/j.cmet.2015.12.006. [PubMed]

16. Evangelista L, Cervino AR, Chondrogiannis S, Marzola MC, Maffione AM, Colletti PM, Muzzio PC, Rubello D. Comparison between anatomical cross-sectional imaging and 18F-FDG PET/CT in the staging, restaging, treatment response, and long-term surveillance of squamous cell head and neck cancer: a systematic literature overview. Nucl Med Commun. 2014; 35:123-34. https://doi.org/10.1097/ mnm.0000000000000022. [PubMed]

17. Rusthoven KE, Koshy M, Paulino AC. The role of fluorodeoxyglucose positron emission tomography in cervical lymph node metastases from an unknown primary tumor. Cancer. 2004; 101:2641-9. https://doi.org/10.1002/ cncr.20687. [PubMed]

18. Zhu L, Wang N. 18F-fluorodeoxyglucose positron emission tomography-computed tomography as a diagnostic tool in patients with cervical nodal metastases of unknown primary site: a meta-analysis. Surg Oncol. 2013; 22:190-4. https:// doi.org/10.1016/j.suronc.2013.06.002. [PubMed]

19. Mehanna H, Wong WL, McConkey CC, Rahman JK, Robinson M, Hartley AG, Nutting C, Powell N, Al-Booz H, Robinson M, Junor E, Rizwanullah M, von Zeidler SV, et al. PET-CT Surveillance versus Neck Dissection in Advanced Head and Neck Cancer. N Engl J Med. 2016; 374:1444-54. https://doi.org/10.1056/NEJMoa1514493. [PubMed]

20. Brouwer J, Senft A, de Bree R, Comans EF, Golding RP, Castelijns JA, Hoekstra OS, Leemans CR. Screening for distant metastases in patients with head and neck cancer: is 
there a role for (18)FDG-PET? Oral Oncol. 2006; 42:275-80. https://doi.org/10.1016/j.oraloncology.2005.07.009. [PubMed]

21. Ng SH, Chan SC, Liao CT, Chang JT, Ko SF, Wang HM, Chin SC, Lin CY, Huang SF, Yen TC. Distant metastases and synchronous second primary tumors in patients with newly diagnosed oropharyngeal and hypopharyngeal carcinomas: evaluation of (18)F-FDG PET and extendedfield multi-detector row CT. Neuroradiology. 2008; 50:96979. https://doi.org/10.1007/s00234-008-0426-2. [PubMed]

22. Ng SH, Yen TC, Chang JT, Chan SC, Ko SF, Wang HM, Lee LY, Kang CJ, Wong AM, Liao CT. Prospective study of [18F]fluorodeoxyglucose positron emission tomography and computed tomography and magnetic resonance imaging in oral cavity squamous cell carcinoma with palpably negative neck. J Clin Oncol. 2006; 24:4371-6. https://doi. org/10.1200/jco.2006.05.7349. [PubMed]

23. Szyszko TA, Cook GJR. PET/CT and PET/MRI in head and neck malignancy. Clin Radiol. 2018; 73:60-9. https://doi. org/10.1016/j.crad.2017.09.001. [PubMed]

24. Arens AI, Troost EG, Schinagl D, Kaanders JH, Oyen WJ. FDG-PET/CT in radiation treatment planning of head and neck squamous cell carcinoma. Q J Nucl Med Mol Imaging. 2011; 55:521-8.

25. Daisne JF, Duprez T, Weynand B, Lonneux M, Hamoir M, Reychler H, Gregoire V. Tumor volume in pharyngolaryngeal squamous cell carcinoma: comparison at CT, MR imaging, and FDG PET and validation with surgical specimen. Radiology. 2004; 233:93-100. https:// doi.org/10.1148/radiol.2331030660. [PubMed]

26. Kao J, Vu HL, Genden EM, Mocherla B, Park EE, Packer S, Som PM, Kostakoglu L. The diagnostic and prognostic utility of positron emission tomography/computed tomography-based follow-up after radiotherapy for head and neck cancer. Cancer. 2009; 115:4586-94. https://doi. org/10.1002/cncr.24493. [PubMed]

27. Passero VA, Branstetter BF, Shuai Y, Heron DE, Gibson MK, Lai SY, Kim SW, Grandis JR, Ferris RL, Johnson JT, Argiris A. Response assessment by combined PETCT scan versus CT scan alone using RECIST in patients with locally advanced head and neck cancer treated with chemoradiotherapy. Ann Oncol. 2010; 21:2278-83. https:// doi.org/10.1093/annonc/mdq226. [PubMed]

28. Porceddu SV, Pryor DI, Burmeister E, Burmeister BH, Poulsen MG, Foote MC, Panizza B, Coman S, McFarlane D, Coman W. Results of a prospective study of positron emission tomography-directed management of residual nodal abnormalities in node-positive head and neck cancer after definitive radiotherapy with or without systemic therapy. Head Neck. 2011; 33:1675-82. https://doi.org/10.1002/hed.21655. [PubMed]

29. Abd El-Hafez YG, Moustafa HM, Khalil HF, Liao CT, Yen TC. Total lesion glycolysis: a possible new prognostic parameter in oral cavity squamous cell carcinoma. Oral Oncol. 2013; 49:261-8. https://doi.org/10.1016/j. oraloncology.2012.09.005. [PubMed]
30. Chan SC, Hsu CL, Yen TC, Ng SH, Liao CT, Wang HM. The role of $18 \mathrm{~F}-\mathrm{FDG}$ PET/CT metabolic tumour volume in predicting survival in patients with metastatic nasopharyngeal carcinoma. Oral Oncol. 2013; 49:71-8. https://doi.org/10.1016/j.oraloncology.2012.07.016. [PubMed]

31. Quon A, Fischbein NJ, McDougall IR, Le QT, Loo BW Jr, Pinto H, Kaplan MJ. Clinical role of 18F-FDG PET/ $\mathrm{CT}$ in the management of squamous cell carcinoma of the head and neck and thyroid carcinoma. J Nucl Med. 2007; 48:58S-67S.

32. Chen SW, Hsieh TC, Yen KY, Liang JA, Kao CH. Pretreatment (18)F-FDG PET/CT in whole-body total lesion glycolysis to predict survival in patients with pharyngeal cancer treated with definitive radiotherapy. Clin Nucl Med. 2014; 39:e296-300. https://doi.org/10.1097/ rlu.0000000000000243. [PubMed]

33. Shum WY, Ding HJ, Liang JA, Yen KY, Chen SW, Kao $\mathrm{CH}$. Use of pretreatment metabolic tumor volumes on PET-CT to predict the survival of patients with squamous cell carcinoma of esophagus treated by curative surgery. Anticancer Res. 2012; 32:4163-8.

34. Lee P, Weerasuriya DK, Lavori PW, Quon A, Hara W, Maxim PG, Le QT, Wakelee HA, Donington JS, Graves EE, Loo BW Jr. Metabolic tumor burden predicts for disease progression and death in lung cancer. Int J Radiat Oncol Biol Phys. 2007; 69:328-33. https://doi.org/10.1016/j.ijrobp.2007.04.036. [PubMed]

35. Chung MK, Jeong HS, Park SG, Jang JY, Son YI, Choi JY, Hyun SH, Park K, Ahn MJ, Ahn YC, Kim HJ, Ko YH, Baek $\mathrm{CH}$. Metabolic tumor volume of [18F]-fluorodeoxyglucose positron emission tomography/computed tomography predicts short-term outcome to radiotherapy with or without chemotherapy in pharyngeal cancer. Clin Cancer Res. 2009; 15:5861-8. https://doi.org/10.1158/1078-0432.Ccr-08-3290. [PubMed]

36. Lonneux M, Hamoir $M$, Reychler $H$, Maingon $P$, Duvillard C, Calais G, Bridji B, Digue L, Toubeau M, Gregoire V. Positron emission tomography with [18F] fluorodeoxyglucose improves staging and patient management in patients with head and neck squamous cell carcinoma: a multicenter prospective study. J Clin Oncol. 2010; 28:1190-5. https://doi.org/10.1200/jco.2009.24.6298. [PubMed]

37. Meignan M, Cottereau AS, Versari A, Chartier L, Dupuis J, Boussetta S, Grassi I, Casasnovas RO, Haioun C, Tilly H, Tarantino V, Dubreuil J, Federico M, et al. Baseline Metabolic Tumor Volume Predicts Outcome in HighTumor-Burden Follicular Lymphoma: A Pooled Analysis of Three Multicenter Studies. J Clin Oncol. 2016; 34:3618-26. https://doi.org/10.1200/jco.2016.66.9440. [PubMed]

38. Sasanelli M, Meignan M, Haioun C, Berriolo-Riedinger A, Casasnovas RO, Biggi A, Gallamini A, Siegel BA, Cashen AF, Vera P, Tilly H, Versari A, Itti E. Pretherapy metabolic tumour volume is an independent predictor of 
outcome in patients with diffuse large B-cell lymphoma. Eur J Nucl Med Mol Imaging. 2014; 41:2017-22. https:// doi.org/10.1007/s00259-014-2822-7. [PubMed]

39. Mettler J, Muller H, Voltin CA, Baues C, Klaeser B, Moccia A, Borchmann P, Engert A, Kuhnert G, Drzezga AE, Dietlein M, Kobe C. Metabolic Tumour Volume for Response Prediction in Advanced-Stage Hodgkin Lymphoma. J Nucl Med. 2019; 60:207-11. https://doi. org/10.2967/jnumed.118.210047. [PubMed]

40. Mikhaeel NG, Smith D, Dunn JT, Phillips M, Moller H, Fields PA, Wrench D, Barrington SF. Combination of baseline metabolic tumour volume and early response on $\mathrm{PET} / \mathrm{CT}$ improves progression-free survival prediction in DLBCL. Eur J Nucl Med Mol Imaging. 2016; 43:1209-19. https://doi.org/10.1007/s00259-016-3315-7. [PubMed]

41. Higgins KA, Hoang JK, Roach MC, Chino J, Yoo DS, Turkington TG, Brizel DM. Analysis of pretreatment FDGPET SUV parameters in head-and-neck cancer: tumor SUVmean has superior prognostic value. Int J Radiat Oncol Biol Phys. 2012; 82:548-53. https://doi.org/10.1016/j. ijrobp.2010.11.050. [PubMed]

42. Koyasu S, Nakamoto Y, Kikuchi M, Suzuki K, Hayashida K, Itoh K, Togashi K. Prognostic value of pretreatment 18F-FDG PET/CT parameters including visual evaluation in patients with head and neck squamous cell carcinoma. AJR Am J Roentgenol. 2014; 202:851-8. https://doi. org/10.2214/ajr.13.11013. [PubMed]

43. Mena E, Taghipour M, Sheikhbahaei S, Jha AK, Rahmim A, Solnes L, Subramaniam RM. Value of Intratumoral Metabolic Heterogeneity and Quantitative 18F-FDG PET/ CT Parameters to Predict Prognosis in Patients With HPVPositive Primary Oropharyngeal Squamous Cell Carcinoma. Clin Nucl Med. 2017; 42:e227-e34. https://doi.org/10.1097/ rlu.0000000000001578. [PubMed]

44. Zhang H, Seikaly H, Nguyen NT, Abele JT, Dziegielewski PT, Harris JR, O'Connell DA. Validation of metabolic tumor volume as a prognostic factor for oral cavity squamous cell carcinoma treated with primary surgery. Oral Oncol. 2016; 57:6-14. https://doi.org/10.1016/j. oraloncology.2016.03.013. [PubMed]

45. Allal AS, Slosman DO, Kebdani T, Allaoua M, Lehmann W, Dulguerov P. Prediction of outcome in head-and-neck cancer patients using the standardized uptake value of 2-[18F]fluoro-2-deoxy-D-glucose. Int J Radiat Oncol Biol Phys. 2004; 59:1295-300. https://doi.org/10.1016/j. ijrobp.2003.12.039. [PubMed]

46. Deron P, Mertens K, Goethals I, Rottey S, Duprez F, De Neve W, Vermeersch H, Van de Wiele C. Metabolic tumour volume. Prognostic value in locally advanced squamous cell carcinoma of the head and neck. Nucl Med (Stuttg). 2011; 50:141-6. https://doi.org/10.3413/Nukmed-0367-10-11. [PubMed]

47. Kim SY, Roh JL, Kim JS, Ryu CH, Lee JH, Cho KJ, Choi $\mathrm{SH}$, Nam SY. Utility of FDG PET in patients with squamous cell carcinomas of the oral cavity. Eur J Surg Oncol. 2008;
34:208-15. https://doi.org/10.1016/j.ejso.2007.03.015. [PubMed]

48. Machtay M, Natwa M, Andrel J, Hyslop T, Anne PR, Lavarino J, Intenzo CM, Keane W. Pretreatment FDGPET standardized uptake value as a prognostic factor for outcome in head and neck cancer. Head Neck. 2009; 31:195-201. https://doi.org/10.1002/hed.20942. [PubMed]

49. Dibble EH, Alvarez AC, Truong MT, Mercier G, Cook EF, Subramaniam RM. 18F-FDG metabolic tumor volume and total glycolytic activity of oral cavity and oropharyngeal squamous cell cancer: adding value to clinical staging. J Nucl Med. 2012; 53:709-15. https://doi.org/10.2967/ jnumed.111.099531. [PubMed]

50. Ryu IS, Kim JS, Roh JL, Cho KJ, Choi SH, Nam SY, Kim SY. Prognostic significance of preoperative metabolic tumour volume and total lesion glycolysis measured by (18)F-FDG PET/CT in squamous cell carcinoma of the oral cavity. Eur J Nucl Med Mol Imaging. 2014; 41:452-61. https://doi.org/10.1007/s00259-013-2571-z. [PubMed]

51. Tang C, Murphy JD, Khong B, La TH, Kong C, Fischbein NJ, Colevas AD, Iagaru AH, Graves EE, Loo BW Jr, Le QT. Validation that metabolic tumor volume predicts outcome in head-and-neck cancer. Int J Radiat Oncol Biol Phys. 2012; 83:1514-20. https://doi.org/10.1016/j.ijrobp.2011.10.023. [PubMed]

52. Alluri KC, Tahari AK, Wahl RL, Koch W, Chung CH, Subramaniam RM. Prognostic value of FDG PET metabolic tumor volume in human papillomavirus-positive stage III and IV oropharyngeal squamous cell carcinoma. AJR Am J Roentgenol. 2014; 203:897-903. https://doi.org/10.2214/ ajr.14.12497. [PubMed]

53. Adams MC, Turkington TG, Wilson JM, Wong TZ. A systematic review of the factors affecting accuracy of SUV measurements. AJR Am J Roentgenol. 2010; 195:310-20. https://doi.org/10.2214/ajr.10.4923. [PubMed]

54. Romesser PB, Qureshi MM, Shah BA, Chatburn LT, Jalisi S, Devaiah AK, Subramaniam RM, Truong MT. Superior prognostic utility of gross and metabolic tumor volume compared to standardized uptake value using PET/CT in head and neck squamous cell carcinoma patients treated with intensity-modulated radiotherapy. Ann Nucl Med. 2012; 26:527-34. https://doi.org/10.1007/s12149-0120604-5. [PubMed]

55. La TH, Filion EJ, Turnbull BB, Chu JN, Lee P, Nguyen K, Maxim P, Quon A, Graves EE, Loo BW Jr, Le QT. Metabolic tumor volume predicts for recurrence and death in head-and-neck cancer. Int J Radiat Oncol Biol Phys. 2009; 74:1335-41. https://doi.org/10.1016/j. ijrobp.2008.10.060. [PubMed]

56. Zhang H, Seikaly H, Abele JT, Jeffery DT, Harris JR, O'Connell DA. Metabolic tumour volume as a prognostic factor for oral cavity squamous cell carcinoma treated with primary surgery. J Otolaryngol Head Neck Surg. 2014; 43:33. https://doi.org/10.1186/s40463-014-0033-7. [PubMed] 
57. Kikuchi M, Koyasu S, Shinohara S, Usami Y, Imai Y, Hino M, Itoh K, Tona R, Kanazawa Y, Kishimoto I, Harada H, Naito Y. Prognostic value of pretreatment 18F-fluorodeoxyglucose positron emission tomography/CT volume-based parameters in patients with oropharyngeal squamous cell carcinoma with known p16 and p53 status. Head Neck. 2015; 37:1524-31. https://doi.org/10.1002/ hed.23784. [PubMed]

58. Larson SM, Erdi Y, Akhurst T, Mazumdar M, Macapinlac HA, Finn RD, Casilla C, Fazzari M, Srivastava N, Yeung HW, Humm JL, Guillem J, Downey R, et al. Tumor Treatment Response Based on Visual and Quantitative Changes in Global Tumor Glycolysis Using PET-FDG Imaging. The Visual Response Score and the Change in Total Lesion Glycolysis. Clin Positron Imaging. 1999; 2:159-71.

59. Blahak J, Zelinka J, Gumulec J, Machacek C, Danek Z, Bulik O. HPV, protein p16 and squamous cell carcinoma of the oral cavity. Biomed Pap Med Fac Univ Palacky Olomouc Czech Repub. 2020; 164:292-99. https://doi. org/10.5507/bp.2019.026. [PubMed]
60. Vidal Loustau AC, Dulguerov N, Curvoisier D, McKee T, Lombardi T. Low prevalence of HPV-induced oral squamous cell carcinoma in Geneva, Switzerland. Oral Dis. 2019; 25:1283-90. https://doi.org/10.1111/odi.13084. [PubMed]

61. Collins GS, Reitsma JB, Altman DG, Moons KG. Transparent Reporting of a multivariable prediction model for Individual Prognosis or Diagnosis (TRIPOD): the TRIPOD statement. Ann Intern Med. 2015; 162:55-63. https://doi.org/10.7326/m14-0697. [PubMed]

62. Creff G, Devillers A, Depeursinge A, Palard-Novello X, Acosta O, Jegoux F, Castelli J. Evaluation of the Prognostic Value of FDG PET/CT Parameters for Patients With Surgically Treated Head and Neck Cancer: A Systematic Review. JAMA Otolaryngol Head Neck Surg. 2020; 146:471-9. https://doi.org/10.1001/jamaoto.2020.0014. [PubMed] 